\title{
A note about density staircases in the Gulf of Naples: 20 years of persistent weak salt-fingering layers in a coastal area
}

\author{
Florian Kokoszka, Daniele Iudicone, Adriana Zingone, Vincenzo Saggiomo, Maurizio Ribera d'Alcalà, \\ Fabio Conversano
}

Stazione Zoologica Anton Dohrn, Naples, Italy

\begin{abstract}
This is a short communication about the inter-annual recurring presence at a coastal site in the Gulf of Naples of density staircases visible below the mixed surface layer of the water-column, from the end of summer to the beginning of winter, each year during nearly two decades of survey (2001 to 2020). We repetitively observed sequences from 1 to 4 small vertical staircases structures $\left(\sim 3 \mathrm{~m}\right.$ thick) in the density profiles $\left(\sim \Delta 0.2 \mathrm{~kg} \mathrm{~m}^{-3}\right)$, located between $10 \mathrm{~m}$ to $50 \mathrm{~m}$ deep below the seasonal mixed layer depth. We interpret these vertical structures as the result of double-diffusive processes that could host salt-fingering regime (SF) due to warm salty water parcels overlying on relatively fresher and colder layers. This common feature of the Mediterranean basin (i.e., the thermohaline staircases of the Tyrrhenian Sea), may sign here for the lateral intrusions of nearshore water masses. These stably stratified layers are characterized by values of the density ratio $R_{p}$ from 5.0 to 10.0 , slightly higher than the critical range ( $1.0-$ 3.0) generally expected for fully developed salt-fingers. SF mixing, such as parameterized, appears to inhibit weakly the effective eddy diffusivity with negative averaged value $\left(\sim-1 \times 10^{-8} \mathrm{~m}^{2} \mathrm{~s}^{-1}\right)$ varying in a main interval between $-1 \times 10^{-7}$ and $-1 \times 10^{-9} \mathrm{~m}^{2} \mathrm{~s}^{-1} \mathrm{during}$ the two decades. Even contributing weakly to the turbulent mixing of the area, we hypothesize that SF could influence the seasonal stratification by intensifying the density of deep layers. Downward transfer of salt could have an impact on the nutrient supply for the biological communities, that remains to be determined.
\end{abstract}

\section{INTRODUCTION}

Double diffusive mixing in the ocean is driven by the difference between molecular diffusivities of heat and salt (Stommel et al., 1956), the diffusion of heat being roughly 100 times faster than for salt (Zhang et al., 1998). This can be illustrated by the case of relatively warm water parcels that stabilize locally the water-column, tending to rapidly diffuse their heat content, while the slower diffusion of the salty content renders the vertical stability prone to gravitational collapse. This situation leads to a transfer of salt toward the bottom, denominated as saltfingering (SF) after the famously known chimney structure (Stommel et al., 1956; Stern, 1960; Linden, 1973). Another situation can occur too, when relatively cold and fresh water overlays on warmer and saltier parcels. Thermal content diffusion tends to stabilize upward, bringing salty parcels toward the surface, and an oscillatory diffusive (DDF) instability is generated. Once established in the water-column, these diffusive regimes can be identified in the vertical profiles of density by a series of well-mixed layers, whose staircases signature can extend from relatively vertical thin or fine-scale layers (e.g., 5 to $100-\mathrm{m}$ thick intrusions, Ruddick, Richards (2003)) to larger structures (e.g. 300-m thick in the Tyrrhenian Sea in Durante et al. (2019)). This process has been widely observed since decades in the ocean (e.g., Schmitt et al. (2005) in the Atlantic Ocean, Timmermans et al. (2003) and Lenn et al. (2009) in the Arctic), and particularly in the Mediterranean Sea (Meccia et al., 2016; Falco, 2016), but field observations and time series acquisition remain of importance to investigate properly the temporal variability associated to these diffusive phenomena, as pointed out by the study of Durante et al. (2019). Weak turbulent environment remains a key condition for a density staircase establishment against strong mixing processes (Timmermans et al., 2003), but the compilation of all in-situ observations demonstrates decades of their persistence in the Mediterranean basin with spatially distributed coherent patterns (Buffett et al., 2017). Even if these diffusive phenomena have been shown to contribute weakly to the ocean circulation (Lenn et al., 2009; Boog et al., 2021), its influence to the buoyancy flux can be significant in non-sheared environment and should be taken in account properly in the water-column budgets (Inoue et al., 2007). Due to the direct transfer of salt, they provide toward the deep layers, and even weakly turbulent, double diffusive processes are effective and of importance to supply nutrients for the biological activity in the internal part of the water column (Fernández Castro et al., 2015). Historically, studies of this phenomenon focused on the open and interior part of the ocean basins, but lakes, shallow seas and coastal areas can be concerned too (Carniel et al., 2008; Schmid et al., 2010; Umlauf et al., 2018). The Gulf of Naples is a midlatitude semi-enclosed shallow basin in the Western Mediterrean Sea having a subtropical regime and almost no tides (Figure 1). The area presents a marked salinity contrast due to the combination of the salty Tyrrhenian Sea waters, with its own feature of inshore/offshore water exchange with the open ocean, located on its southern side (Cianelli et al., 2015), and the freshwater inputs from a densely inhabited coastal area, on its northern part and from nearby rivers (Cianelli et al., 2012, 2017). The recent 
study of Kokoszka et al. (2021) in this location shows weak turbulent observations during the seasonal destratification, associated to the presence of doublediffusive layers below the intrusion of warm salty layers present in sub-surface from late summer to early winter. We extend this half-year period analysis to the long-term time series in the Gulf of Naples with the use of temperature and salinity profiles. These observations were made in the framework of the long-term ecosystem research Marechiara (LTER-MC) initiative that produced a historical time series of the Mediterrean coastal ecosystem of the Gulf of Naples through a weekly sampling of the water column started in 1984 and running until now (Ribera d'Alcalà et al., 2004; Zingone et al., 2019). We will focus here on the last two decades (January 2001 to March 2020), and identify the layers of the water-column prone to salt-finger regimes, to show their variability, and estimate the associated eddy diffusivity, to determine their possible contribution to the vertical mixing in such coastal area

\section{MATERIALS AND METHODS}

\section{General hydrology}

Conductivity-temperature-depth (CTD) profiles were carried out at the LTER-MC sampling point in the Gulf of Naples (75 m deep, $2 \mathrm{~km}$ off the coast, see Figure 1) with a Seabird SBE-911+ mounted on a 12-bottle carousel, with all sensors calibrated. The raw profiles were processed using the Seabird data processing software to obtain 1-m bin-averaged data. The weekly survey refers to the casts MC465 (January 2001) to MC1359 (February 2020) and includes a total of 895 CTD profiles. The Gibbs sea water oceanographic toolbox (Mc-Dougall, Barker, 2011) was used to calculate the conservative temperature $\Theta\left({ }^{\circ} \mathrm{C}\right)$, the absolute salinity $A_{S}\left(\mathrm{~g} \mathrm{~kg}^{-1}\right)$, the potential density $\sigma_{0}(\mathrm{~kg}$ $\mathrm{m}^{-3}$ ), and the potential temperature $\theta_{0}\left({ }^{\circ} \mathrm{C}\right)$. When mentioned thereafter, temperature $T$ and salinity $S$ refer to $\Theta$ and $A_{S}$. Mixed layer depth (MLD, m) was calculated following the method of de Boyer Mont' egut et al. (2004)
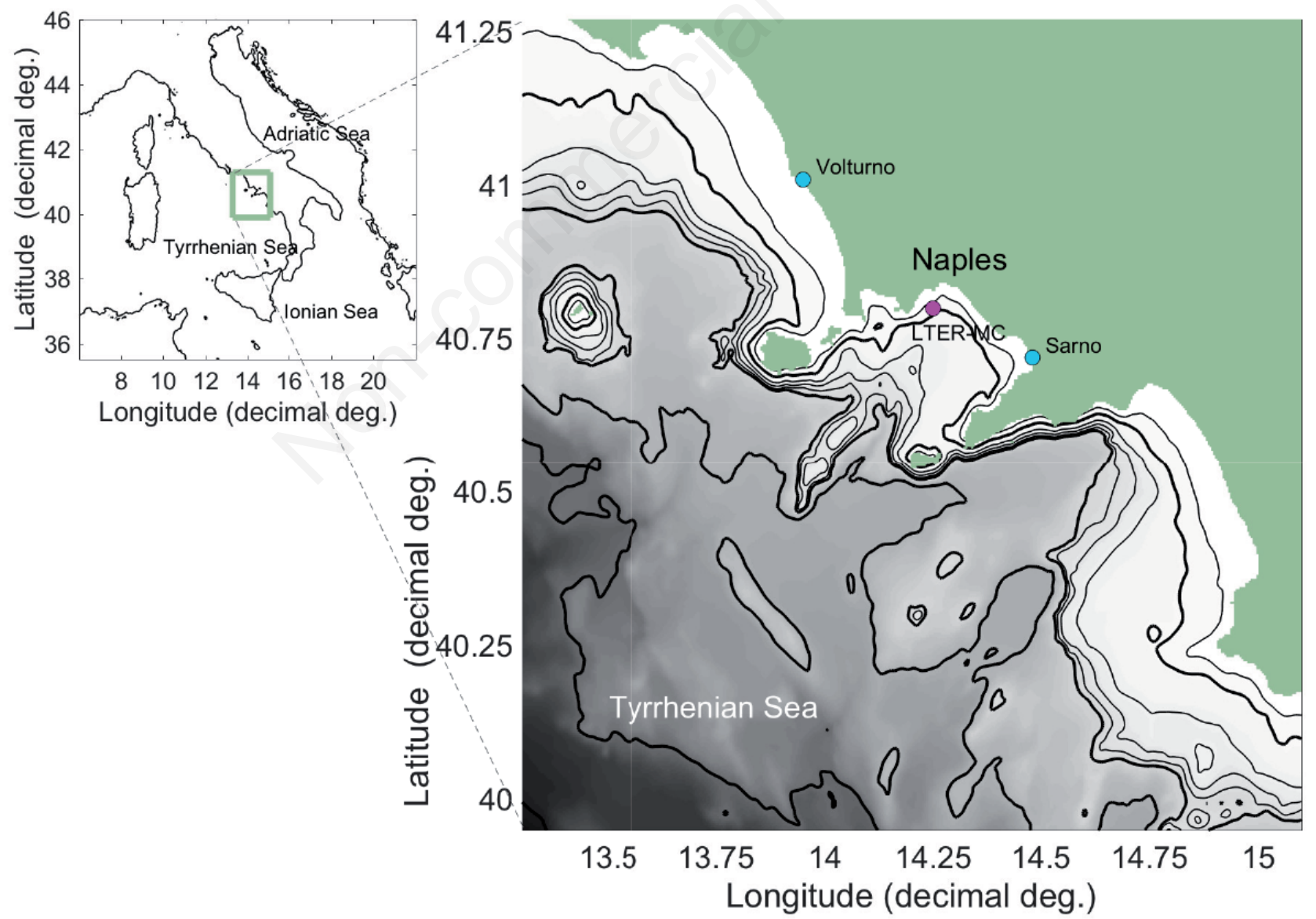

Figure 1. Bathymetry of the Gulf of Naples (GEBCO grid (GEBCO, 2020)) along the Tyrrhenian Sea in the Mediterranean basin). The $75 \mathrm{~m}$-deep LTER-MC coastal sampling site $\left(14.25^{\circ} \mathrm{E}\right.$, $\left.40.80^{\circ} \mathrm{N}\right)$ is located by the pink dot. Volturno and Sarno's river mouths are shown in blue. Thin lines indicate the 50,200,300 and $400 \mathrm{~m}$ isobaths, thick ones indicate the 100, 500, 1000 and $2000 \mathrm{~m}$ isobaths. 
based on threshold values. Given a vertical profile of density $\sigma_{0}(z)$, we calculated the depth below $z_{\text {ref }}=3 \mathrm{~m}$ where the profile reached a threshold defined as a cumulative of $0.03 \mathrm{~kg} \mathrm{~m}^{-3}$.

\section{Turner's stability regimes}

To produce reliable statistics of the double diffusive regimes, we followed the recommendation of Inoue et al. (2007) who compared successfully CTD estimates and dedicated turbulence measurements. We applied the same 10 -m-scale averaging (indicated by an overline symbol) on temperature and salinity profiles, and conserved only the parts of the water column where the threshold for the minimum temperature gradient was $|\partial \bar{\theta} / \partial z|>0.05^{\circ} \mathrm{C} \mathrm{m}^{-1}$ (Zhang et al., 1998; Inoue et al., 2007). This was shown to improve the statistics by embedding the information contained in the layer, that determines the processes occurring at finer scales (Inoue et al., 2007). We applied the method introduced by Turner (Turner, 1967; 1973) to localize parts of the water column where vertical gradients of $T$ and $S$ are favorable to double-diffusive instability. Combining the vertical gradients and their signs allows the identification of stability regimes, that can be defined from the density ratio $R_{\rho}=(\alpha \partial \theta / \partial z) /(\beta \partial S / \partial z)$ where $\alpha=-\rho^{-1}(\partial \rho / \partial \theta)$ is the thermal expansion coefficient, $\beta=\rho^{-1}(\partial \rho / \partial S)$ is the haline contraction coefficient, and $\partial \theta / \partial z, \partial S / \partial z$ and $\partial \rho / \partial z$ are respectively the vertical gradients of temperature, salinity, and density. This ratio is used to calculate the Turner angles $\left(^{\circ}\right) T u=\arctan \left(\left(1+R_{\rho}\right) /\left(1-R_{\rho}\right)\right)$ (Ruddick, 1983). The value of the Turner angle allows to identify various stability regimes. A diffusive convection regime (e.g., fresh cold layers over warm salty layer) arises when $-90^{\circ}<T u<-45^{\circ}$. A double-diffusive regime (e.g., salty warm layer over cold fresh layer) arises when $45^{\circ}<T u<90^{\circ}$. Within each of these regimes, the instability is higher when $|T u|$ is close to 90 degrees. A stable regime occurs when $|T u|<45^{\circ}$, whereas a gravitationally unstable regime occurs when $|T u|>90^{\circ}$. Generally, salt-fingering is considered active when $1<R_{\rho}<3$ (Inoue et al., 2007; Carniel et al., 2008), but as illustrated thereafter in Figure 2 , our observations exhibit small density staircases $(\sim 3 \mathrm{~m})$ associated to slightly larger values of $R_{\rho}(3.0-5.0)$, which should sign for a weak salt-fingering regime, but marked by persisting structures, that were visible repetitively weeks after weeks. Given that values $1<R_{\rho}<10$ are frequently observed (Kelley, 1990), and the large variability of the worldwide observations (You, 2002; Nakano, Yoshida, 2019), we included then all the cases $1<R_{\rho}<30$.

\section{Salt-fingering diffusivity and salty flux}

From the estimates of $R_{\rho}$, diffusivities of heat, salt and density associated with salt-fingering have been extensively reviewed and are still discussed until now (Kunze, 2003,
Nakano, Yoshida, 2019). Once we have identified parts of the water column prone to SF regime, we apply the parameterization of Zhang et al. (1998) to obtain the effective salt and thermal diffusivities, respectively $K_{S}^{\mathrm{SF}}=$ $K^{*} /\left(1+\left(R_{\rho} / R_{C}\right)^{n}\right)$ and $K_{T}^{\mathrm{SF}}=\gamma^{\mathrm{SF}}\left(K_{S}^{\mathrm{SF}}\right) / R_{\rho}$, where $n=6, R_{C}=$ $1.6, K^{*}=1 \times 10^{-4} \mathrm{~m}^{2} \mathrm{~s}^{-1}$ a upper limit for the SF diffusivity, and $\gamma^{\mathrm{SF}}$ is computed as $\gamma^{\mathrm{SF}}=2.709 e^{-2.512 R \rho}+0.5128$ (Radko, Smith, 2012). Finally, we infer the effective eddy diffusivity of the density, $K_{\rho}^{\mathrm{SF}}=\left(K_{T}^{\mathrm{SF}} R_{\rho}-K_{S}^{\mathrm{SF}}\right) /\left(R_{\rho}-1\right)(\mathrm{Eq} 8$ in Nakano, Yoshida (2019)). As pointed out by the authors in their review, values of $K_{\rho}^{\mathrm{SF}}$ are negative, indicating that SF reduces the potential energy of the system by transferring salt downward in the water-column, and consequently intensifies density stratification. To illustrate that, we recall a general expression for the diffusivity (valid for heat, salt, or density) as a combination of salt-fingering (SF), doublediffusive (DDF), and other processes than double-diffusion (e.g., internal wave turbulence): $K_{\rho}^{\mathrm{TOTAL}}=K_{\rho}^{\mathrm{Turb}}+K_{\rho}^{\mathrm{SF}}+$ $K_{\rho}^{\mathrm{DDF}}$ (Merryfield et al., 1999; Merryfield, 2000; Inoue et al., 2007); $K_{\rho}^{\text {TOTAL }}$ is generally dominated by the contribution of $K_{\rho}^{\text {Turb, }}$, and can be reduced by the negative values of $K_{\rho}^{\mathrm{SF}}$. Please note that double-diffusive (DDF) will not be discussed in this work, and has been reviewed in detail by the mentioned authors. An estimate of buoyancy flux for salt is given by Kunze (1987) for SF developed on "thick" layers $(>1 \mathrm{~m})$, as $g \beta F_{S}=2 v g \beta(\partial S / \partial z)\left(R_{\rho}^{1 / 2}+\left(R_{\rho}-\right.\right.$ $\left.1)^{1 / 2}\right)^{2}$ (Kunze (1987), and Eq. 97 in Nakano, Yoshida (2019)), with $\bar{S}$ a mean value in the layer, $g$ the gravitational acceleration $\left(9.80 \mathrm{~m} \mathrm{~s}^{-2}\right), v$ the kinematic molecular viscosity $\left(1.05 \times 10^{-6} \mathrm{~m}^{2} \mathrm{~s}^{-1}\right)$. Here $F_{S}$ is the vertical salt flux $\left(\mathrm{g} \mathrm{kg}^{-1} \mathrm{~m} \mathrm{~s}^{-1}\right), \beta F_{S}$ the density flux of salt $\left(\mathrm{m} \mathrm{s}^{-1}\right)$, and $g \beta F_{S}$ the buoyancy flux $\left(\mathrm{m}^{2} \mathrm{~s}^{-3}\right)$.

\section{RESULTS}

\section{Staircase layers during the seasonal cycle}

Established from the weekly profiles of the period 2001-2020, the climatological monthly variations of salinity show a remarkable intrusion in sub-surface (thick blue contour in Figure 2, top), with values close to the maximum, between 38.05 and $38.1 \mathrm{~g} \mathrm{~kg}^{-1}$, visible from September to November below $10 \mathrm{~m}$ depth, and above the $20 \mathrm{~m}$ to $45 \mathrm{~m}$ layer of relative less salty water $\left(<38.0 \mathrm{~g} \mathrm{~kg}^{-1}\right)$.

The thickness of this salty tongue increases in time following the deepening of the seasonal thermocline up to November (MLD in thick gray line in Figure 2, top), progressively filling the water column, besides the first 5 m. Temperature (black contours in Figure 2, top) shows a more classical seasonal cycle, with a mean maximum of around $26^{\circ} \mathrm{C}$ in July and August, decreasing to $24.0^{\circ} \mathrm{C}$ in September, then to $20.0^{\circ} \mathrm{C}$ and $18.0^{\circ} \mathrm{C}$ in October and November. From August to November these intrusions of 
salty water from 10 to $60 \mathrm{~m}$ create the unstable conditions for SF regime, whose water-column occupation is shown in plain blue in Figure 2 (top), below the MLD (thick gray).

The overview of the mean seasonal hydrological state allowed us to identify some general vertical distribution of SF regimes during the seasonal cycle. We illustrate this situation by showing a typical example of small staircases (e.g., during the cast MC1126 in Figure 2, bottom). From around 25 to $45 \mathrm{~m}$ deep, both gradients of $T$ and $S$ are compatible with the host of SF regime. A sharp variation of nearly $0.2 \mathrm{~g} \mathrm{~kg}^{-1}$ is visible between 30 and $32 \mathrm{~m}$, followed by a more moderate one of $0.1 \mathrm{~g} \mathrm{~kg}^{-1}$ from 32 to $37 \mathrm{~m}$, associated both with a temperature loss of nearly $1.0^{\circ} \mathrm{C}$. The density profile is then marked by a sequence of thin and curvy staircases, progressing stably toward depth by steps of $0.20 \mathrm{~kg} \mathrm{~m}^{-3}$ on vertical scales from 1 to $3 \mathrm{~m}$. In terms of Turner angles, stronger value of $60^{\circ}$ is obtained at $27 \mathrm{~m}$ where the instability presumably initiates from the salty and warm input, and progressively decreases to around $50^{\circ}$ at $40 \mathrm{~m}$ where $T-S$ gradients stop to host the SF regime. Associated values of $R_{\rho}$ vary from 3.0 to 5.0 where density staircases are the sharpest, then
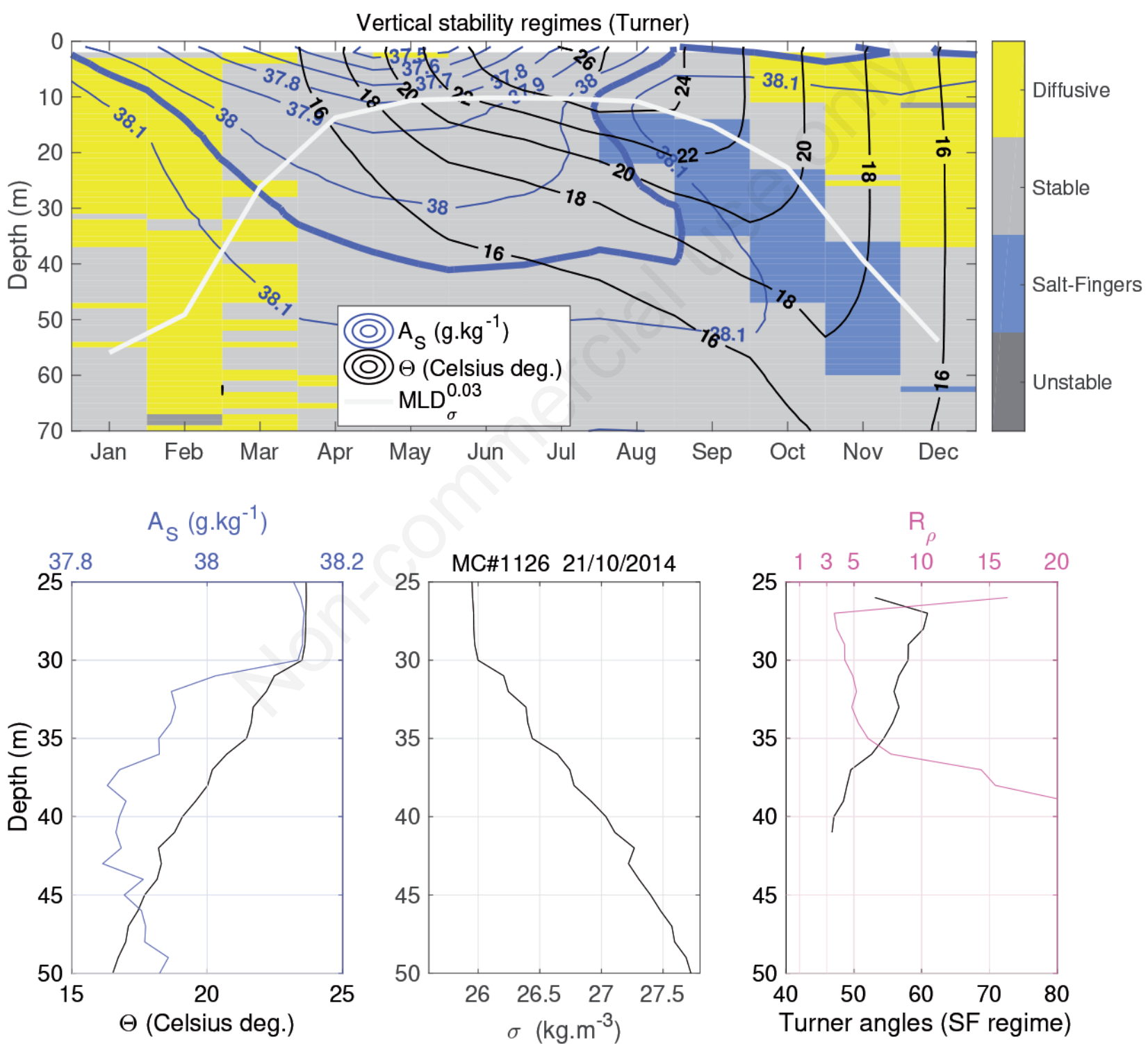

Figure 2. Top: Seasonal water-column occupation by the four stability regimes of Turner, showing vertical layers prompt to possibly host double-diffusive instabilities (SF or DDF), inferred from the monthly climatological proles established with the weekly CTD data from 2001 to 2020 (MC465 to MC1359). Black and blue: contours of the climatological temperature and salinity proles. Thick blue: 38:05 g $\mathrm{kg}^{-1}$ haline level, showing the salty intrusion. Light gray: seasonal mixed layer depth (MLD). Bottom: Illustration of a density staircase situation (cast MC1126). Left: temperature and salinity proles; Center: density; Right: Turner angles and density ratio R (SF regime). 
increase above 10.0 at the host ending. These values are slightly above the range in which SF are expected to be the most active $(1.0-3.0)$, but density observations are marked by small curvy staircases, whose vertical structure have been smoothed by the 1-m scale vertical averaging of the data. Given these values of $R_{\rho}$ and the shape of density profiles, we consider that we observe here a relatively weak SF regime, and this situation tends to repeat and persist in time during the season.

\section{Unfolding the layers: nearly 20 years of staircase layers}

This persistence during the two last decades is clearly demonstrated in Figure 3 with the vertical distribution of $R_{\rho}$ showing the vertical hosting of the SF regime below the mean MLD (gray line), mainly from August to November. Even being weak in general ( $T u$ in the range $45-60^{\circ}$ ), the most intense Turner angles values are more frequent in October and November than during the summer (see the vertical patterns in Figure 3, and the red to blue distributions in Figure 4). Mean values of $R_{\rho}$ are between 5.0 and 10.0, and occurrences $<5.0$ are more frequent in October and November. Estimates of salt and thermal diffusivities reach mean values centered around $1 \times 10^{-8} \mathrm{~m}^{2} \mathrm{~s}^{-1}$ and $4 \times 10^{-9} \mathrm{~m}^{2} \mathrm{~s}^{-1}$ during these months, while the intensity is weaker and close to $1 \times 10^{-11} \mathrm{~m}^{2} \mathrm{~s}^{-1}$ in August. This marks a seasonal differentiation in our observations, the post-summer period being prompter to host the more intense SF regimes. When estimating the effective eddy diffusivity for the density, values of $K^{\mathrm{SF}}$ are negative, indicating that $\mathrm{SF}$ reduces the potential energy of the system by transferring salt downward in the watercolumn. Mean contribution is low $\left(-3 \times 10^{-8} \mathrm{~m}^{2} \mathrm{~s}^{-1}\right)$, compared to the averaged turbulent diffusivity expected in such coastal system (from $1 \times 10^{-6} \mathrm{~m}^{2} \mathrm{~s}^{-1}$ to $1 \times 10^{-4} \mathrm{~m}^{2}$ $\mathrm{s}^{-1}$ ). The range of the associated buoyancy flux for salt is around $-6 \times 10^{-9} \mathrm{~m}^{2} \mathrm{~s}^{-3}$ from September to October (see
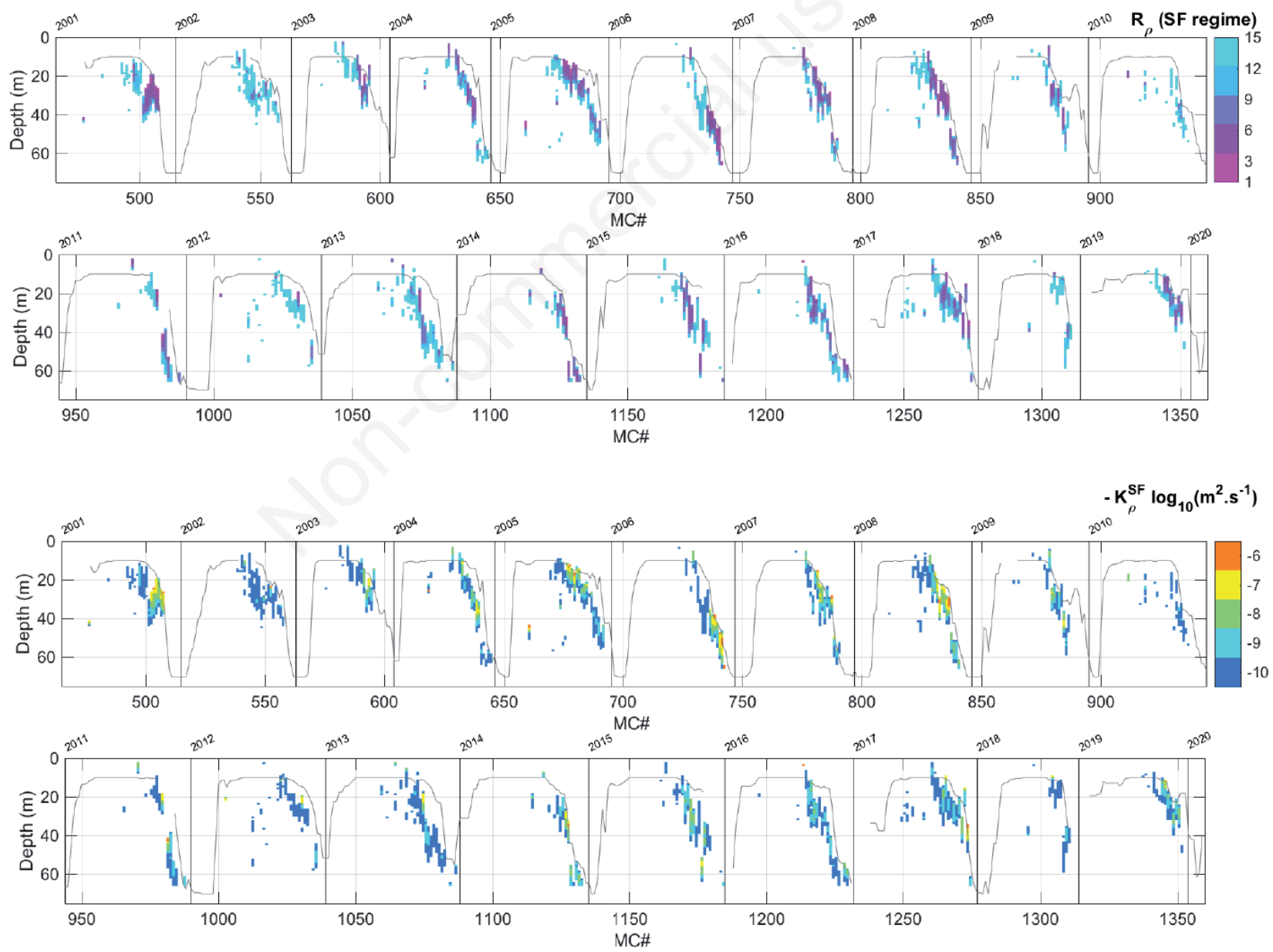

Figure 3. Time series of the vertical profiles of $R_{\rho}$ (Top, pink to light blue chart) and the effective eddy diffusivity $K^{\mathrm{SF}}$ (Bottom, blue to orange chart), for the SF regime. For each parameter, decades 2001-2010 and 2011-2020 are split between upper and lower panels, respectively. Y-axis indicates the depth of profiles, bottom X-axis indicates the sequence of weekly MC casts (MC465 to MC1359), and years are indicated on top. Gray line: mixed layer depth. 
the yellow, orange and blue distributions in Figure 4), and is centered closer to $-1 \times 10^{-8} \mathrm{~m}^{2} \mathrm{~s}^{-3}$ in August (red). Consequently, SF mixing, such as parameterized, appears to inhibit weakly the turbulent mixing of the area $\left(K \rho^{T O T A L}\right.$ $\left.=K \rho^{T U R B}+K \rho^{S F}+K \rho^{D D P}\right)$, but increase the stability of the deep layers by intensifying the density stratification due to the transfer of salt toward the bottom. The inter-annual values (black plots in Figure 4) of $K^{\mathrm{SF}}$ confirms these averages ranging between $-1 \times 10^{-9} \mathrm{~m}^{2} \mathrm{~s}^{-1}$ and $-1 \times 10^{-6} \mathrm{~m}^{2}$ $\mathrm{s}^{-1}$ during the two decades, and the low averaged buoyancy flux for salt $\left(\sim-6 \times 10^{-9} \mathrm{~m}^{2} \mathrm{~s}^{-3}\right)$ compared to the expected total buoyancy fluxes due to heat and freshwater by atmospheric forcing at the surface (of the order of $\sim 1 \times 10^{-7} \mathrm{~m}^{2} \mathrm{~s}^{-3}$, see Kokoszka et al. (2021)).

\section{DISCUSSION}

The long-term monitoring (20 years) of the coastal station Marechiara in the Gulf of Naples reveals noteworthy repetitive observations of small staircases vertical structures $(\sim 3 \mathrm{~m})$ in the density field $(\sim \Delta 0.2 \mathrm{~kg}$ $\mathrm{m}^{-3}$ ), whose presence is associated to surrounding layers of relatively warm and salty waters in sub-surface (from
10 to $50 \mathrm{~m}$ deep) from August to November, each year. We interpret these observations as the result of doublediffusive processes, i.e. here salt-fingering instabilities.

Such fine-scale structures may sign here for lateral intrusions (Merryfield, 2000; Umlauf et al., 2018), or interleaving (Ruddick, Richards, 2003; Ruddick, Kerr, 2003), whose inshore advection remains to be determined. These stably stratified layers are characterized by density ratio $R_{\rho}$ from 5.0 to 10.0 , close to some observations made in the Artic Ocean (Timmermans et al., 2008; Shibley et al., 2017). As pointed out by Bebieva, Timmermans (2017), taking in account the horizontal gradients of $\mathrm{T}$ and $\mathrm{S}$ (intrusions), a critical value for the instbility does not necessarily need to be close to 1.0 , the higher values of $R_{\rho}$ being the signature of T-S intrusions. This may be what we observe here, differing from the T-S staircases, typical of the neighboring Tyrrhenian Sea (Zodiatis, Gasparini, 1996; Durante et al., 2019). In such configuration, dedicated parameterization taking account of horizontal gradients and using intermediate and higher $R_{\rho}$ values should be investigated.

As showed in the work of Merryfield et al. (1999) double-diffusive phenomena can have regional influences
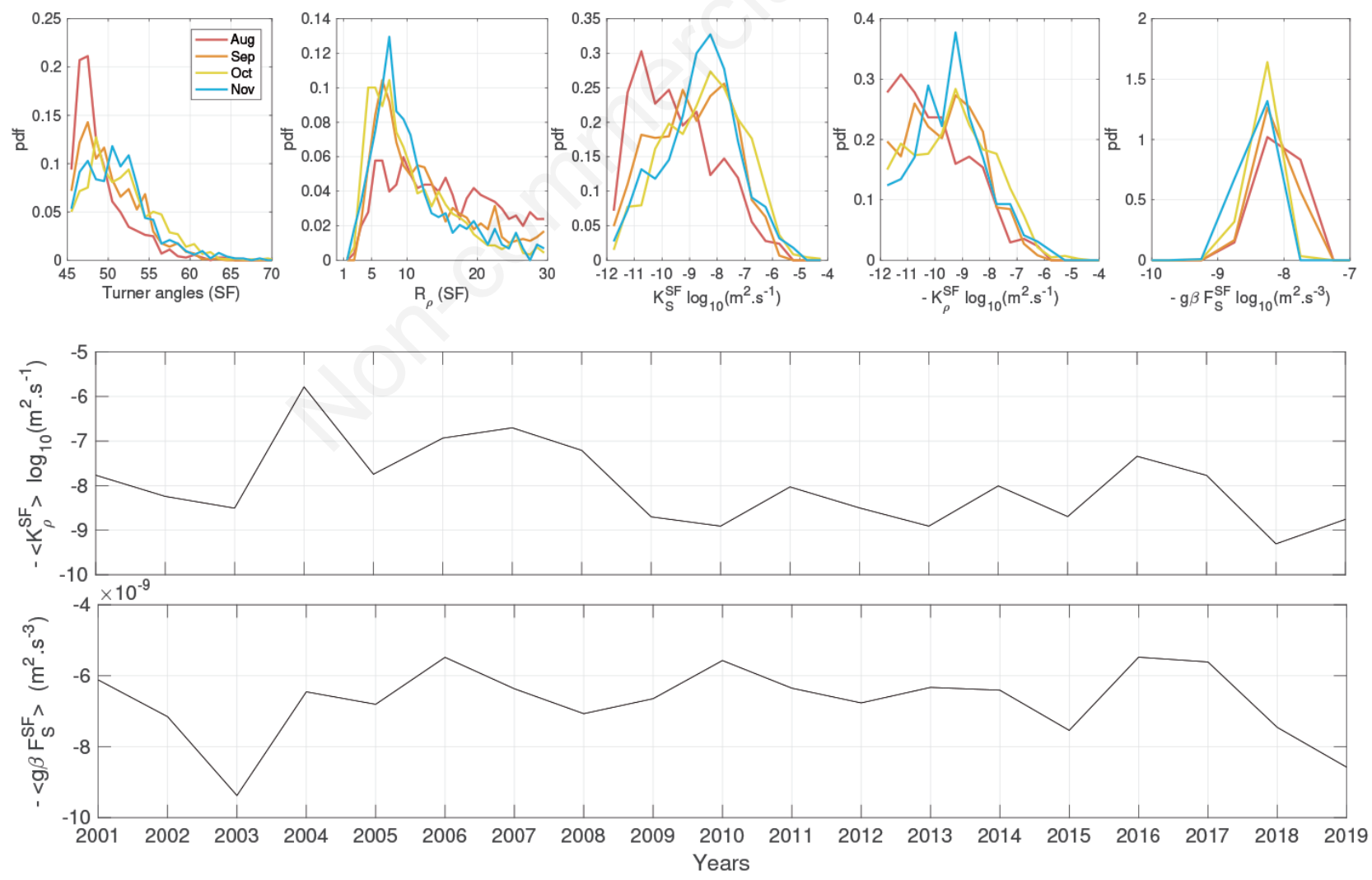

Figure 4: Top: Probability density function (PDF) associated with the following parameters in the SF regime: Turner angles, $R_{\rho}$, effective salt diffusivity $\left(K_{S}^{\mathrm{SF}}\right)$, effective eddy diffusivity $\left(K_{\rho}^{\mathrm{SF}}\right)$, and buoyancy flux for salt. Distributions have been established for the months of August to November, from 2001 to 2019, when SF regime was possible. Bottom: Inter-annual variability of the year-averaged mean values of $K_{\rho}^{\mathrm{SF}}$ and buoyancy flux for salt $g \beta F_{S}^{\mathrm{SF}}$ (note the negative values). 
on temperature and salinity. The recent observations of Ferron et al. (2021) in the Algerian Sea inferred that SF mixing can significantly modify the basin water masses within a period of 2 years. Noteworthy, a rise in the values of the fluxes in the Tyrrhenian interior was observed by Durante et al. (2021) during the 2003-2016 period, due to higher salt and temperature gradients. These studies highlight the temporal and regional variability of SF, and strengthen the idea that from boundaries to deep sea locations, observational efforts on SF phenomena could be valuable to improve the parameterizations modeling the development and effect of staircases (Kantha et al., 2011; Radko et al., 2014) in global and coastal circulation models.

Given the averaged values of $R_{\rho}(\sim 5.0)$ and the observed values of turbulent mixing $\left(<K_{\rho}^{\text {Turb }}>\right.$ between 0.2 to $0.8 \times 10^{-5} \mathrm{~m}^{2} \mathrm{~s}^{-1}$, in Kokoszka et al. (2021)), the inhibition due to negative $<K^{\mathrm{SF}}>$ in the mixing mixture (Inoue et al., 2007) is expected to be negligible, even some intermittent unstable occurrences $\left(R_{\rho}\right.$ close to 1.0$)$ can be present in the SF layer below the MLD. Even if mixing would be unaffected, the density stratification enforcement due to the transfer of salt could influence the generation and propagation of internal waves in such stratifiedcompatible layers (Kunze, 2003; Malki-Epshtein, Uppert, 2004; Maurer, Linden, 2014), followed by their breaking in the deepest layers, more relaxed to the buoyancy-control of vertical motions. When the SF-compatible layers are located closer to the bottom (e.g., around $50 \mathrm{~m}$ in November), influence of boundary processes could be at work too, as suggested by the turbidity observations in Kokoszka et al. (2021). The step size of the observed structures could be a clue of the coexistence between weakly sheared internal wave and double-diffusion processes, as mentioned in the review of Kunze (2003). This feature of the shallow non-tidal area of the Gulf of Naples could provide an interesting in-situ experimental field to investigate and understand better the dynamic behind background gradients of tracers and velocity, and the growing of SF instabilities (Inoue et al., 2008; Ma, Peltier, 2021).

In general, implications for biological communities could be important. Compared to fluxes associated with mechanical forcing or mesoscale eddies, Oschlies et al. (2003) found the same magnitude attributed to doublediffusive processes, that showed a salt-finger driven enhancement of the upper ocean nutrient supply. As estimated in the work of Fernández Castro et al. (2015), nitrate diffusion mediated by salt fingers is responsible for $20 \%$ of the new nitrogen supply in several areas of the Atlantic and Indian Oceans. More recently, Taillandier et al. (2020) showed that the nitrates supply across thermohaline staircases in the Western Mediterranean Sea contributed at $25 \%$ to the budget of the Levantine intermediate water.
The Gulf of Naples stands as a shallow bay connected to the open Tyrrhenian area, and Cianelli et al. (2017) have shown the importance of the interplay between coastal and offshore water masses to promote phytoplankton diversity.

Their study identified the role of the horizontal mixing to enhance or dilute the favorable conditions for dominant species, and under this hypothesis we propose that salty intrusions (i.e., horizontal gradients) should be investigated in terms of their stability relative to the vertically surrounding layers. Given the downward transfer of salt due to SF regime in this shallow area where the photic layer prevails in the growing dynamic of the biological populations (Zingone et al., 1995, 2010), the importance of such a supply to the communities inhabiting the deep layers is a primer to determine. Because SF activity depends on the density ratio rather than on the stratification stability, its sensitivity to the future expected warming/freshening trends of the surface waters in the Mediterranean Sea (Volosciuk et al., 2016) should be addressed, as shown by the inter-annual decadal variability already observable at the coastal site in the Gulf of Naples.

Corresponding author: Florian Kokoszka, florian.kokoszka@szn.it

Keywords: Coastal ecosystem; Mediterranean Sea; time series; hydrological data; turbulence; stratification; mixing; doublediffusion; salt-fingers.

Author's contribution: All the authors have read and approved the final version of the manuscript and agreed to be accountable for all aspects of the work.

Availability of data and materials: Data sets for this research are available on request.

Conflict of interest: The authors declare no potential conflict of interest.

Acknowledgments: The authors would like to thank the LTER$\mathrm{MC}$ team that includes, besides the main authors: D. D'Alelio, C. Balestra, M. Cannavacciuolo, R. Casotti, I. Di Capua, F. Margiotta, M. G. Mazzocchi, M. Montresor, A. Passarelli, I. Percopo, M. Saggiomo, D. Sarno, F. Tramontano, G. Zazo, all based at the Stazione Zoologica Anton Dohrn of Naples. Special thanks must be given to A. Passarelli and the commandants and crews of the R/V Vettoria for all their dedicated work at sea. The research program LTER-MC is supported by the Stazione Zoologica Anton Dohrn.

Received: 31 July 2021.

Accepted: 29 October 2021.

This work is licensed under a Creative Commons Attribution NonCommercial 4.0 License (CC BY-NC 4.0).

${ }^{\circ}$ Copyright: the Author(s), 2021

Licensee PAGEPress, Italy

Advances in Oceanography and Limnology, 2021; 12:10008

DOI: 10.4081/aiol.2021.10008 


\section{REFERENCES}

Bebieva Y, Timmermans ML, 2017. The relationship between double-diffusive intrusions and staircases in the Arctic Ocean. Journal of Physical Oceanography 47:867-878.

Buffett GG, Krahman G, Klaeschen D, Schroeder K, Sallares V, papenberg C, et al., 2017. Seismic oceanography in the Tyrrhenian Sea - thermohaline staircases, eddies and internal waves. Journal of Geophysical Research: Oceans 122:85038523 .

Carniel S, Sclavo M, Kantha L, Prandke Hartmut, 2008. Doublediffusive layers in the Adriatic Sea. Geophysical Research Letters 35:102605.

Cianelli D, D'Alelio D, Uttieri M, Sarno D, Zingone A, Zambianchi E, et al., 2017. Disentangling physical and biological drivers of phytoplankton dynamics in a coastal system. Scientific Reports 7:15868.

Cianelli D, Falco P, Iermano I, Mozzillo P, Uttieri M, Buonocore B, et al., 2015. Inshore/offshore water exchange in the Gulf of Naples. Journal of Marine Systems 145:37-52.

Cianelli D, Uttieri M, Buonocore B, Falco P, Zambardino G, Zambianchi E, 2012. Dynamics of a very special Mediterranean coastal area: the Gulf of Naples, p.129-150. In: Williams G (ed.), Mediterranean Ecosystems: dynamics, management and conservation.

Compilation Group GEBCO, 2020. GEBCO 2020 Grid. Available at: https://www.gebco.net.

Copernicus Climate Change Service (C3S), 2017. ERA5: fifth generation of ECMWF atmospheric re-analyses of the global climate. Copernicus Climate Change Service Climate Data Store (CDS). Available at: https://climate.copernicus.eu/.

De Boyer Montegut C, Madec G, Fischer AS, Lazar A, Iudicone D, 2004. Mixed layer depth over the global ocean: an examination of profile data and profile-based climatology. Journal of Geophysical Research 109:c12003.

Durante S, Olivieri P, Nair R, Sparnocchia S, 2021. Mixing in the Tyrrhenian interior due to thermohaline staircases. Frontiers in Marine Science. Available at: https://www.frontiersin.org /articles/10.3389/fmars.2021.672437/full.

Durante S, Schroeder K, Mazzei L, Pierini S, Borghini M, Sparnocchia S, 2019. Permanent thermohaline staircases in the Tyrrhenian Sea. Geophysical Research Letters 46:15621570 .

Falco P, 2016. Water mass structure and deep mixing processes in the Tyrrhenian Sea: results from the VECTOR project. Deep Sea Research Part I Oceanographic Research Papers 113: 7-21.

Fernández Castro B, Mouriño-Carballido B, Marañon E, Chouciño P, Gago J, Ramirez T, et al., 2015. Importance of salt fingering for new nitrogen supply in the oligotrophic ocean. Nature Communications 6:8002.

Ferron B, Bouruet-Aubertot P, Schroeder K, Bryden H, Cuypers Y, Borghini M, 2021. Contribution of thermohaline staircases to deep water mass modifications in the Western Mediterranean Sea from microstructure observations. Frontiers in Marine Science 8:664509.

Inoue R. Kunze E, Laurent L, Schmitt R, Toole J, 2008. Evaluating salt-fingering theories. Journal of Marine Research 66:413-440

Inoue R, Yamazaki H, Wolk F, Kono T, Yoshida J, 2007. An estimation of buoyancy flux for a mixture of turbulence and double-diffusion. Journal of Physical Oceanography 37:611624.

IOC, SCOR, IAPSO, 2010. The international thermodynamic equation of seawater 2010: calculation and use of thermodynamic properties. Intergovernmental Oceanographic Commission, Manuals and Guides no.56, UNESCO, 196 pp.

Kanta L, Carniel S, Sclavo M, 2011. A note on modelling doublediffusive mixing in the global ocean. Ocean Modelling 36:40-48.

Kelley D, 1990. Fluxes through diffusive staircases, a new formulation. Journal of Geophysical Research 95:3365-3371.

Kokoszka F, Conversano F, Iudicone D, Ferron B, BouruetAubertot P, McMillan J, 2021. Microstructure observations of the summer-to-winter destratification at a coastal site in the gulf of Naples. Earth and Space Science Open Archive, $36 \mathrm{pp}$.

Kunze E, 1987. Limits on growing, finite-length salt fingering, a Richardson Number constraint. Journal of Marine Research 45:533-556.

Kunze E, 2003. A review of oceanic salt-fingering theory. Progress in Oceanography 56:399-417.

Lenn, YD, Wiles PJ, Torres-Valdes S, Abrahamsen EP, Rippeth TP, Simpson JH, et al., 2009. Vertical mixing at intermediate depths in the Arctic boundary current. Geophysical Research Letters 36:105601.

Linden PF, 1973. On the structure of salt fingers. Deep Sea Research 20:325-332.

Ma Y, Peltier W, 2021. Gamma instability in an inhomogeneous environment and salt-fingering staircase trapping: determining the step size. Physical Review Fluids 6:033903.

Malki-Epshtein L, Huppert H, 2004. Internal waves and velocity scales of double diffusive intrusions. APS Division of Fluid Dynamics Meeting Abstracts 57:eb004.

Maurer B, Linden P, 2014. Intrusion-generated waves in a linearly stratified fluid. Journal of Fluid Mechanics 752: 282-295.

McDougall TJ, Barker PM, 2011. Getting started with TEOS10 and the Gibbs seawater (GSW) oceanographic toolbox. Available at: http://www.teos-10.org/pubs/Getting_Started. pdf.

Meccia V, Simoncelli S, Sparnocchia S, 2016. Decadal variability of the Turner angle in the Mediterranean Sea and its implications for double diffusion. Deep Sea Research Part I: Oceanographic Research Papers 114:64-77.

Merryfield W, 2000. Origin of thermohaline staircases. Journal of Physical Oceanography 30:1046-1068.

Merryfield W, Holloway G, Gargett A, 1999. A global ocean model with double-diffusive mixing. Journal of Physical Oceanography 29:1124-1142.

Nakano H, Shimada K, Nemoto M, Yoshida J, 2014. Parametrization of the eddy diffusivity due to double diffusive convection. Mer 52:91-98.

Nakano H, Yoshida J, 2019. A note on estimating eddy diffusivity for oceanic double-diffusive convection. Journal of Oceanography 75:375-393.

O'Brien T, Lorenzoni L, Isensee K, Valdes L, 2016. What are marine ecological time series telling us about the ocean? A status report. IOC Unesco Technical Series 129. Available at: https://igmets.net/report.

Oschlies A, Dietze H, Kähler P, 2003. Salt-finger driven 
enhancement of upper ocean nutrient supply. Geophysical Research Letters 30:2204.

Pujiana K, Moum JN, Smyth WD, 2018. The role of turbulence in redistributing upper-ocean heat, freshwater, and momentum in response to the MJO in the equatorial Indian ocean. Journal of Physical Oceanography 48:197-220.

Radko T, Bulters A, Flanagar J, Campin JM, 2014. Doublediffusive recipes. Part I: large-scale dynamics of thermohaline staircases. Journal of Physical Oceanography 44:1269-1284.

Radko T, Smith D, 2012. Equilibrium transport in doublediffusive convection. Journal of Fluid Mechanics 692:5-27.

Ribera d'Alcalà M, Conversano F, Corato F, Licandro P, Mangoni O, Marino D, et al., 2004. Seasonal patterns in plankton communities in pluriannual time series at a coastal Mediterranean site (Gulf of Naples); an attempt to discern recurrences and trends. Scientia Marina 68:65-83.

Ruddick B, 1983. A practical indicator of the stability of the water column to double-diffusive activity. Deep Sea Research Part A. Oceanographic Research Papers 30:1105-1107.

Ruddick B, Anis A, Thompson K, 2000. Maximum likelihood spectral fitting: the Batchelor spectrum. Journal of Atmospheric and Oceanic Technology 17:1541-1555.

Ruddick B, Kerr O, 2003. Oceanic thermohaline intrusions: theory. Progress in Oceanography 56:483-497.

Ruddick B, Richards K, 2003. Oceanic thermohaline intrusions: observations. Progress in Oceanography 56:499-527.

Ruddick B, Turner J, 1979. The vertical length scale of doublediffusive intrusions. Deep Sea Research Part A. Oceanographic Research Papers 26:903-913.

Schmid M, Busbridge M, Est A, 2010. Double-diffusive convection in Lake Kivu. Limnology and Oceanography 55:225-238.

Schmitt R, Ledwell J, Montgomery E, Polzin K, Toole J, 2005. Enhanced diapycnal mixing by salt-fingers in the thermocline of the Tropical Atlantic. Science 308:685-688.

Shibley N, Timmermans ML, Carpenter JR, Toole J, 2017. Spatial variability of the Arctic Ocean's double diffusive staircase. Journal of Geophysical Research: Oceans 122:980-994.

Stern M, 1960. The salt-fountain and thermohaline convection. Tellus 12:172-175.

Stommel H, Arons A, Blanchard D, 1956. An oceanographical curiosity, the perpetual salt fountain. Deep Sea Research 3:152-153.

Taillandier V, Prieur L, D'Ortenzio F, Ribera d'Alcalà M, PulidoVillena E, 2020. Profiling float observation of thermohaline staircases in the Western Mediterranean Sea and impact on nutrient fluxes. Biogeosciences 17:3343-3366.

Timmermans ML, Garrett C, Carmack E, 2003. The thermohaline structure and evolution of the deep-water in the Canada Basin, Arctic Ocean. Deep Sea Research Part I: Oceanographic Research Papers 50:1305-1321.

Timmermans ML, Toole J, Krishfield R, Winsor P, 2008. Icetethered profiler observations of the double-diffusive staircase in the Canada Basin thermocline. Journal of Geophysical Research 113:c00a002.

Turner J, 1967. Salt fingers across a density interface. Deep Sea Research and Oceanographic Abstracts 14:599-611.

Turner J, 1973. Buoyancy effects in fluids. Cambridge University Press, Cambridge, UK, 368 pp.

Turner J, 1983. Oceanic fine and microstructure, p.35-55. In: Brewer PG (ed.), Oceanography, the present and future: from the proceedings of 'Will we use the oceans wisely-the next fifty years in oceanography', September 29-October 2, 1980, Woods Hole, Massachusetts, USA.

Umlauf L, Holtermann P, Gillner C, Prien R, Merckelbach L, Carpenter J, 2018. Diffusive convection under rapidly varying conditions. Journal of Physical Oceanography 48:1731-1747.

Van der Boog C, Dijkstra H, Pietrzak J, Katsman C, 2021. Double-diffusive mixing makes a small contribution to the global ocean circulation. Communications Earth and Environment 2:46.

Volosciuk C, Maraun D, Semenov VA, Tilinina N, Gulev SK, Latif M, 2016. Rising Mediterranean Sea surface temperatures amplify extreme summer precipitation in Central Europe. Scientific Reports 6:32450.

You Y, 2002. A global ocean climatological atlas of the Turner angle: implications for double-diffusion and water-mass structure. Deep Sea Research Part I: Oceanographic Research Papers 49:2075-2093.

Zingone A, Casotti R, Ribera d'Alcalà M, Scardi M, Marino D, 1995. St. Martin's Summer - the case of an autumn phytoplankton bloom in the Gulf of Naples (Mediterranean Sea). Journal of Plankton Research 17:575-593.

Zingone A, D'Alelio D, Mazzocchi MG, Montresor M, Sarno D, 2019. Time series and beyond: multi-faceted plankton research at a marine Mediterranean LTER site. Nature Conservation 34:273-310.

Zingone A, Dubroca L, Iudicone D, Margiotta F, Corato F, Ribera d'Alcalà M, et al., 2010. Coastal phytoplankton do not rest in winter. Estuaries and Coasts 33:342-361.

Zhang J, Schmitt R, Huang R, 1998. Sensitivity of the GFDL modular ocean model to parametrization of double-diffusive processes. Journal of Physical Oceanography 28:589-605.

Zodiatis G, Gasparini G, 1996. Thermohaline staircase formations in the Tyrrhenian Sea. Deep Sea Research Part I: Oceanographic Research Papers 43:655-678. 